Original Research Paper

\title{
Qualitative Evaluation of 5S Application Considering the Experience of Electrical Construction Experts
}

\author{
${ }^{1}$ Mohammad Sadra Fardhosseini, ${ }^{2}$ Mostafa Soltaninejad, \\ ${ }^{3}$ Ali Karji, ${ }^{3}$ Zahra Ghorbani and ${ }^{4}$ Omidreza Ghanadiof \\ ${ }^{I}$ Department of Construction Management, University of Washington, USA \\ ${ }^{2}$ Highways East Group, Jacobs Engineering Group Inc., USA \\ ${ }^{3}$ Department of Architectural Engineering, The Pennsylvania State University, USA \\ ${ }^{4}$ Department of Technology, University of Central Missouri, USA
}

Article history

Received: $18-12-2020$

Revised: $16-02-2021$

Accepted: 17-02-2021

Corresponding Author:

Mostafa Soltaninejad

Highways East Group, Jacobs

Engineering Group Inc., USA

Email: mostafa.soltaninejad@jacobs.com

\begin{abstract}
The 5S lean tool is one of the most common lean construction techniques, which can lead to safe work environments if used effectively on project sites. The purpose of this study is to provide a checklist to maximize the outcomes of the $5 \mathrm{~S}$ approach concerning safety requirements. A grounded theory technique was used to analyze the interview data. Eighteen electrical construction experts with the snowball of construction workers, safety representatives, supervisors, site and project managers were interviewed. Ultimately, the present study simplifies $5 \mathrm{~S}$ implementation for first-time users and outperforms the outputs of the existing users. It is expected that the presented $5 \mathrm{~S}$ checklist will provide practical actions for safer construction sites.
\end{abstract}

Keywords: 5S Approach, Qualitative, Interview, Grounded Theory, Checklist

\section{Introduction}

In the U.S., electrical contracting is an industry valued at over $\$ 171$ billion annually based on the National Electrical Contractors Association (NECA) report, made up of over 70,000 electrical contracting firms employing over 650,000 electrical workers. The construction industry has a higher number of accidents than other sectors (Albrechtsen et al., 2019) and has a non-fatal occupational injury rate of 2 per 100 employees (BLS, 2018). OSHA (2016) stated that workrelated deaths and injuries cost $\$ 151$ billion. Healthier safety climates are correlated with diminished accident rates (Sheykhfard et al., 2020; Jones et al., 2019; Varonen and Mattila, 2000), making safety improvement the priority of lean construction techniques, especially in the electrical construction industry.

Lean construction is an organizational method designed to reduce waste, maintain flow, decrease cost, enhance quality and safety on construction projects (Aslam et al., 2020a, b; Innella et al., 2019; Ghanadiof, 2017; Srinivasan et al., 2016; Lee et al., 2019). One practical solution to minimize death and injuries at construction workplaces is applying lean techniques such as the $5 \mathrm{~S}$ system. Table 1 lists the original five Japanese $\mathrm{S}$ words, their English translations and the $5 \mathrm{~S}$ method definitions. The five phases are crucial and must be applied separately and in order. The first three phases are operational, the fourth maintains the state reached with the previous phases and the fifth phase leads to continuous improvement at work (Jiménez et al., 2015).

$5 \mathrm{~S}$ process is a lean tool that aims to show hidden problems (Meiling et al., 2012) and organize work areas so as to increase efficiency and lessen waste (Salem et al., 2014; 2005). Unquestionably, organized workstations can lead to high-quality production, reducing safety hazards and risks (Enshassi and Abu Zaiter, 2014). However, a few studies have utilized $5 \mathrm{~S}$ as one of the lean methods to improve construction safety (Gambatese et al., 2017; Michalska and Szewieczek, 2007; Brown and O'Rourke, 2007; Srinivasan et al., 2016; Jiménez et al., 2015).

The 5S approach has numerous benefits. For instance, sorting helps to minimize broken tools, scrap and obsolete jigs and fixtures (Harrington, 1991). This aids employees to work and move easier because of smoother item flow (Dudek-Burlikowska, 2006). The advantage of set-in order is easy-to-use of tools and make other resources visible (Lancucki, 2001). Furthermore, shining the work area not only reduces waste, but also acts as a motivation for the employees (Dudek-Burlikowska, 2006). Noteworthy is that developing a standard helps employees know their responsibilities and perform their duties in a routine (Dudek-Burlikowska, 2006; Lancucki, 2001). Although workers should maintain discipline, indeed a reward system should take place to motivate them. 
Table 1: $5 \mathrm{~S}$ terms and definitions

\begin{tabular}{lll}
\hline Japanese term & English term & Definition \\
\hline Seiri & Sort & Remove unnecessary tools and keep essential items \\
Seiton & Set in order (Storage) & Arrange materials and equipment in an orderly fashion to make the job easier to perform \\
Seiso & Sweep (Shine) & Keep work areas and equipment clean to reduce waste \\
Seiketsu & Standardize & Allocate rules to keep everything clean and organized \\
Shitsuke & Sustain & Inspect the workstation to ensure the rules are being followed \\
\hline
\end{tabular}

Table 2: Position distribution of participants among investigated companies

\begin{tabular}{llllr}
\hline Role & Company 1 & Company 2 & Company 3 & Total \\
\hline Construction worker & 1 & 0 & 1 & 2 \\
Safety representative & 3 & 1 & 2 & 6 \\
Supervisor & 2 & 2 & 1 & 5 \\
Project manager & 1 & 1 & 1 & 3 \\
Site manager & 1 & 0 & 1 & 2 \\
Total & 8 & 4 & 6 & 18 \\
\hline
\end{tabular}

From the literature review, a comprehensive list of objectives, methodologies and results of miscellaneous case studies around the world from 2003 to 2020 focusing on the $5 \mathrm{~S}$ lean strategy are summarized in Appendix A. The main objectives of $5 \mathrm{~S}$ are improving productivity, reducing waste, continuous improvement, improving working procedures and enhancing safety (Aslam et al., 2020a). However, among all of these objectives, the priority of $5 \mathrm{~S}$ is to improve the health and safety of workers. Conspicuously, safer environments can positively affect the motivation of the workers (Jiménez et al., 2015). There are a few studies that mainly investigate the objective of safety enhancement through the 5S procedure (Michalska and Szewieczek, 2007; Brown and O'Rourke, 2007; Leino et al., 2014; Jiménez et al., 2015; Tezel et al., 2016), especially in the United States of America ( $\mathrm{Ng}$ et al., 2010; Srinivasan et al., 2016; Ruiz et al., 2020).

Previously, (Al Heet et al., 2020) found that companies utilize collaborative practices, visual management techniques such as $5 \mathrm{~S}$ and root cause analysis to solve their safety problems. Tezel et al. (2016) stated that the 5S visual system improved workplace conditions with lessened item transaction process times, savings in workspaces and a better health and safety condition. Also, (Gupta and Jain, 2015) reported that several positive changes were made to the operating procedures, tool organization, cleaning schedules and material handling. For instance, tool searching time from shop floor has been decreased from 30 to $5 \mathrm{~min}$.

Although previous studies have studied the effect of lean practices on safety climate, research should be conducted to clarify $5 \mathrm{~S}$ necessary actions in the construction sites considering safety cautions (Srinivasan et al., 2016). The notion of applying the 5S method as one of the lean construction techniques is still needed more studies to minimize construction and manufacturing incidents. According to the literature, there is a gap in upgrading the $5 \mathrm{~S}$ method based on electrical construction experts' experience since they know the shortcomings of this approach due to problems that have already been occurred in their projects when $5 \mathrm{~S}$ was applied. Therefore, this study aims to extract a practical checklist for $5 \mathrm{~S}$ steps for enhancing safety at electrical workplaces based on the findings extracted from interviews.

\section{Materials and Methods}

The research methodology diagram is demonstrated in Fig. 1. The details of the grounded theory method, data collection, interview analysis process, the interview results and the extracted checklist are included in the following sections.

\section{Participants and Case Studies}

Safety and lean experts were contacted in different firms ranged in size and expertise, including general contractors and electrical construction companies and finally, three companies in Washington and Oregon states accepted our request for an interview with their employees, supervisors and managers. Overall, safety and lean managers in 51 companies were contacted, of which 18 accepted the invitation to participate in the interview (35\% response rate). The criteria to select these participants were their experience of using the $5 \mathrm{~S}$ method in real projects (one successful and one unsuccessful) and at least 5 years of experience in the electrical construction field. They were working at different levels as construction workers, safety representatives, supervisors and project managers. The participants with an average of 10 years of experience working at different levels were interviewed. The description of the studied construction companies is described in Table 2. These 18 experts are selected from three companies with small (20 to 99 employees), medium (100 to 499 employees) and large (500+ employees). 


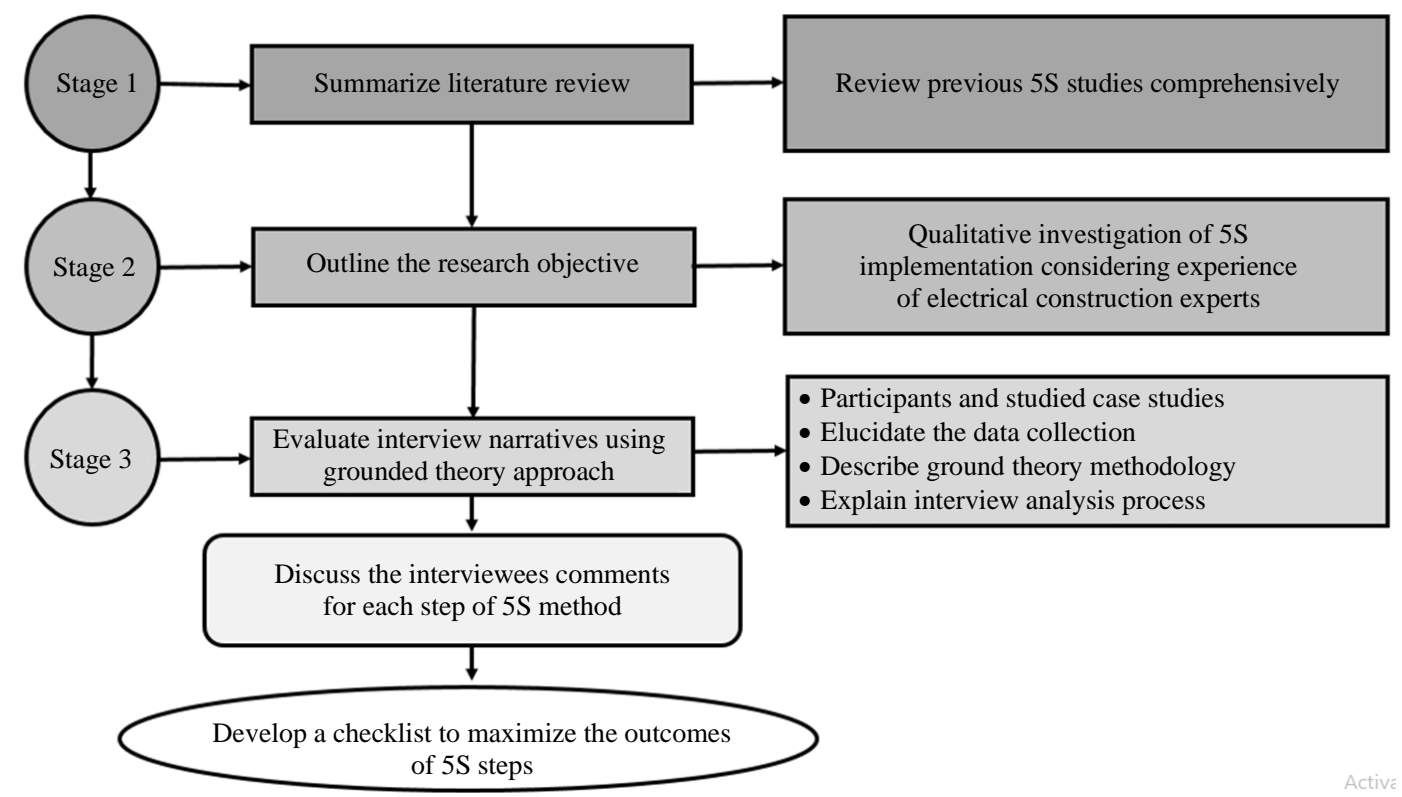

Fig. 1: A schematic explanation of the research methodology

\section{Data Collection}

Interviews were recorded using semi-structured openended questions that explored the nature of the interviewee's interaction with the $5 \mathrm{~S}$ lean tool of their construction projects18 experts in lean and safety practices were questioned a set of core questions. Participants were asked to describe their role for the $5 \mathrm{~S}$ application, which step of $5 \mathrm{~S}$ they were responsible for, to whom they were reported and how they provided information about their performance, how they were rewarded/sanctioned for their performance, how they were trained for $5 \mathrm{~S}$ and/or safety. The interviewees were asked to consider these questions for the two projects with which they were lately implemented 5S lean steps: A successful project and an unsuccessful project. In addition, the participants answered similar questions about each of the two projects. These core questions were followed up with open-ended, follow-up questions that led to a free flow of information controlled by the interviewee. Examples of these questions include: 'What is the purpose of each step of 5S? what are the tips/actions to outperform $5 \mathrm{~S}$ results for the first-time users? and which part of $5 \mathrm{~S}$ steps correlate with safety?

To protect the interviewees' anonymity, their projects and personal information were coded. Afterward, the audios were transcribed and prepared for thematic analysis using the MAXQDA2020 software. They were conducted in English and typically lasted $45 \mathrm{~min}$ to an hour. Some were conducted by phone, others in person on the participants' working location and others were invited to the University of Washington Construction
Research Center (CERC), depending on the interviewee's desire. The questions in the interview guide were not essentially followed in order due to the fact that the emphasis was placed on promoting an atmosphere in which the informant felt safe to talk about the topics honestly and openly (Albrechtsen et al., 2019).

\section{Ground Theory Approach}

The purpose of qualitative content analysis is to examine the central phenomenon in detail and making it clear for the readers (Nelson, 2020; Denzin and Lincoln, 2011). In this research, a grounded theory approach was employed as the qualitative examination technique to create the checklist for $5 \mathrm{~S}$ steps. The main objective of grounded theory is to build a theory about a phenomenon or practice through interviews and/or observation as the data collection tools (Bulawa, 2014). The researcher interpretation should not interfere with predetermined views about what the data will be in the grounded theory and let the themes to be developed naturally based on the description of interviewees (Mac Donald et al., 2020).

Standard methods of grounded theory, containing the coding of data and the categories' development, were applied. Data coding aims to systemize a large amount of data (Albrechtsen et al., 2019) and it was based on three steps defined by (Strauss and Corbin, 1990). The interviewee's comments were coded using three phases: (1) Open coding, (2) axial coding and (3) developing the Themes. In open coding, the transcribed interviews were assessed line by line for simple extraction of what the interviewee is saying and, in some cases, implying or not saying. Open coding requires an in-depth reading of 
the data to comprehend the meaning and context of the interviewee's understanding of $5 \mathrm{~S}$ and its relationship with safety practices. To test the reliability of the coding process, two researchers coded one interview and compared their coding. All 18 interviews were coded at this level.

To improve the accuracy of the interpretations, the validity procedure was considered. Creswell and Báez (2020) recommended multiple approaches simultaneously to improve validity. In this investigation, triangulation and member checking methods were employed to increase the validity and credibility of research findings. Triangulation is defined as the use of multiple approaches or data sources in qualitative research to develop a complete understanding of phenomena (Patton, 1999). In this study, during the interview session, the interviewees reviewed their perspectives about the accuracy and applicability of practical actions of the $5 \mathrm{~S}$ method in real projects. For instance, both the safety representatives and project managers agreed that plan for auditing and using safety checklists are the most important steps in the $5 \mathrm{~S}$ technique and therefore should be controlled daily. Additionally, member checking, also acknowledged as participant validation, is a method for exploring the credibility of results. Data or results are returned to participants to check for accuracy with their experiences.

\section{Interview Analysis Process}

Although open coding distributes the large amounts of data into smaller homogenous pieces, the second phase, axial coding, should be utilized. This stage is the process where data are put back together in new ways after open coding by making connections between classifications. This is done by using a coding pattern involving conditions, context, action/interactional strategies and consequences. Axial coding investigates how these classifications attach and relate, which leads to the identification of larger categories that can be utilized to describe the broader themes which stem from the data (Mac Donald et al., 2020). In the present study, the interviews were evaluated line by line with coding that what the interviewee was feeling, saying, or thinking. These results were then clustered into classifications of related axial codes. As an example, interviewees' comments were coded into first an open code (5S management tool, reduce accidents), then to the axial code (Safety enhancement); finally, to the broader theme (effects).

\section{Results}

In the following sections, each step of the $5 \mathrm{~S}$ process will be discussed in order to explain how these steps have been performed in reality and what was their effect considering the analysis of the interviews. Although 5S has already been applied in practice successfully, it needs to be upgraded to overcome its shortcomings. For instance, the challenge of the sort step is to identify what is required to do the work (Leino et al., 2014).

\section{Sort Step}

The main purpose of the Sort step is to first differentiate required (essential) items from undesirable (needless) items in the workplace and then to remove the unwanted materials and tools that should be stored through organizing and labeling (Srinivasan et al., 2016; Leino et al., 2014). The challenge of the sort step is to identify what is required to do the work (Leino et al., 2014). Removing unwanted items will reduce workers' exposure to messy material leading to a safety improvement in terms of minimizing hazards and risks. In this regard, the project team might use tags of different colors to indicate the number of usage. For example, a red tag may be used to imply when an item should be discarded because it is seldom or not at all used. According to different scenarios, all items with red tags are gathered and the team determines what to do with each item. A yellow tag may mark an item that might require more attention due to its potential safety effects. Table 3 summarizes the Sort step process that is used in the studied construction sites based on the interviewees' comments. Executing the Sort step at the jobsite will easily lead to items getting stored, errors being reduced and search time being decreased, all of which will, in turn, help safety enhancement.

Moreover, interviewees mentioned that Just-in-Time (JiT) delivery could also support the Sort step. JIT refers to a lean technique involving a system for the production or the shipment of an appropriate quantity of parts or goods when necessary. This technique will prevent the items from piling up at the job site. From a safety viewpoint, by adopting JiT, (1) the project team could minimize many ergonomic hazards such as back pain by determining out where to deliver each item using barcode tags; (2) workers may be less vulnerable to slipping, tripping and falling hazards at the project site (less material means less exposure to trips); and (3) workers would be less prone to equipment, leading to a lower risk of getting struck by hazards. Finally, the project team can highlight the "everything on wheels" rule, which suggests that on-wheel equipment should be used to move items at the job site. This rule may also help the workers to avoid ergonomic hazards. Such a rule can help further eliminate ergonomic hazards by supporting both the Sort step and JiT. 


\section{Set in Order (Storage) Step}

Materials and tools are set in order through organizing and labeling (Srinivasan et al., 2016; Leino et al., 2014). The purpose of this step is to arrange items in an easy-tofind way in order to reduce the time required to find the items at the job site. This step enables the workers to not only enhance their work performance but also improve their safety. For example, items should be safely stored to avoid any ergonomic risks, scratches, or strains. To this end, one can ask the following three key questions:

(1) What are the items that need to be positioned?

(2) What is the needed quantity of each item?

(3) Where should the items be placed?

Table 4 presents a summary of the Storage step considering the interviewee's routine work. This step will lead to accurate storage of items, minimizing errors in item selection and reduction of the searching time. Implementing each of these beneficial impacts promotes safety improvement.

\section{Sweep (Shine) Step}

Sweep simply means cleaning clean out any dirt, strain, filth, soot and dust from the working environment (Gupta and Jain, 2015). An interviewee mentioned that this ensures that all waste and external items are eliminated, as the work area is ready for cleaning inspection. This cleaning process also includes the maintenance of the equipment and the facilities. Sweeping and housekeeping are significant safety measures that help workers avoid accidents such as falls or trips over items. The Sweep step also includes making sure the work area is free of hazardous material or equipment. Table 5 presents a summary of the Sweep step. Applying sweep steps on the worksite can lead to a cleaner and more pleasant environment, improving quality and equipment lifespan, all of which support improved safety and lead to fewer injuries.

\section{Standardize Step}

The goal of this step is to standardize the previous three steps-sort, storage and shine-as a culture (Gupta and Jain, 2015). For this reason, a working framework is required in order to turn the steps into a routine or culture. The framework would ensure that all workers use the same process, the same names for the items and the same signage/floor marking format, shapes, colors, etc. In our case, this framework was carried out based on visual management, which helps workers act quickly when facing any hazard. The lean visualization tool is about efficiently transmitting crucial information to the workers by placing various signs and labels around the construction site. Workers may recall signs like workflows, performance targets and specific required actions. This posting includes signs related to safety, schedule and quality. In other words, the efficient communication of the key information to the workers could be accomplished by placing signs and labels around the job site, emphasizing safety, scheduling and quality regulations. These visuals can help workers remember important elements for their operations, such as workflow, performance targets and specific required actions. Table 6 presents a summary of the standardized step. Adopting the workplace standardization step leads to simplifying activities to remove possible risks, achieving standardized work procedures, minimizing errors and improving effectiveness through visual management, all of which enhance safety.

\section{Sustain Step}

The Sustain step's goal is to maintain a workplace with a safety culture that contains $5 \mathrm{~S}$ practices. Meeting this objective requires the commitment of workers to a healthy and safe working environment. This step contains other approaches such as 5 why's and quality improvement. Workers should be prepared to embrace the proposed improvement and to implement the new strategies. The Sustain step is summarized in Table 7.

Using a workstation, workers should not go to the construction trailers to check a part of the implementing drawings. Implementing the Sustain step leads to better working practices and teamwork, a stable and safe environment and the provision of safety managers with the data for safety enhancement purposes.

\section{Discussion}

\section{How to Maximize the Outcomes of 5S Steps?}

The grounded theory examination was focused on the interviewee's narratives to extract practical actions for each step of the $5 \mathrm{~S}$ lean technique. Table 8 are the activities that guide the practitioners to apply each step of the $5 \mathrm{~S}$ method successfully. It is noticeable that these actions are based on the interviewee's lessons learned from previous projects, including challenges, failures and successes who have applied $5 \mathrm{~S}$ in their projects. To ensure the results' accuracy, the 5S steps actions have been back-checked by interviewees.

Even though the practical tips, summarized in Table 8, have had positive effects on the proper performance of the $5 \mathrm{~S}$ process, some barriers need to be addressed. First, it is very hard to achieve the highest level of safety unless it is contractually obligated for the 
project. In other words, safety should be part of a contract. Second, direct financial improvement should be clarified; otherwise, companies will not understand the value of $5 \mathrm{~S}$ and safety integration.

Table 3: Sort step

\begin{tabular}{llll}
\hline When & Why & How & Goal \\
\hline Every morning & To remove undesirable items & Throw it out, when in doubt & $\begin{array}{l}\text { To distinguish "required" items from } \\
\text { "undesirable" items in the workplace } \\
\text { and then remove those items that are } \\
\text { unwanted }\end{array}$ \\
\hline
\end{tabular}

Table 4: Storage parts

\begin{tabular}{llll}
\hline When & Why & How & Goal \\
\hline Every morning & $\begin{array}{l}\text { To minimize the time } \\
\text { taken for searching }\end{array}$ & Elect a place for everything & $\begin{array}{l}\text { To assemble items in a manner such } \\
\text { that they can be found simply }\end{array}$ \\
\hline
\end{tabular}

Table 5: Storage details

\begin{tabular}{llll}
\hline When & Why & How & Goal \\
\hline Every morning & To decrease defects & Clean and correct shortcomings & To make the workplace unrestricted of dirt and stains \\
\hline
\end{tabular}

Table 6: Standardizing information

\begin{tabular}{llll}
\hline When & Why & How & Goal \\
\hline Every day & $\begin{array}{l}\text { To prevent repeating } \\
\text { the same mistakes }\end{array}$ & $\begin{array}{l}\text { Create daily standards based } \\
\text { on the first three steps }\end{array}$ & $\begin{array}{l}\text { To transform the } \\
\text { standards into a culture }\end{array}$ \\
\hline
\end{tabular}

Table 7: Sustain data

\begin{tabular}{llll}
\hline When & Why & How & Goal \\
\hline Every day & To keep the set standards & Generate simple solutions & To have a healthy and safe working environment \\
\hline
\end{tabular}

Table 8: A quick guide for maximizing the effects of the $5 \mathrm{~S}$ program

\begin{tabular}{ll}
\hline 5S steps & Action \\
\hline Sort & - Identify the use-frequency of items or equipment (e.g., daily, weekly, monthly) \\
& - Ask workers from different trades regarding malfunctioning equipment and tools as well as out-of-date/needless \\
& items on site \\
& - Implement the tagging technique (e.g., red tag for unnecessary items and yellow tag for items of safety concern) \\
& - Store items that are problematic to classify temporarily \\
& - Diminish the amount of material and equipment on the site to the minimum mandatory amount \\
& - Sort a disposal process that includes resale, reuse, recycling and waste disposal \\
- Store items in the accessible and controllable spots such as toolboxes, Conexus, lay down areas and storage yards & - Limit the height of storage spaces for heavy items and materials to help workers pick up and move them \\
- Highlight potential safety hazards that workers may face in storage areas \\
- Storing items are based on their function and label them to simplify their easy retrieval \\
- Define cleaning guidelines that include goals and duties \\
- Inspect the work area after every shift \\
- Clean the workplace after every shift \\
- Assure the items, equipment and material are cleaned and ready to use \\
- Check for oil spills, excess fluids, leaks, equipment damage, worn-out cables, burned-out bulbs, etc. \\
- Shine lighting to identify dirt and dust easily \\
- Place visual signs through the work area that remind workers of proper and improper workstation setup \\
- Allocate roles and expectations of individuals' accountability to keep the culture of cleanliness \\
- Systematize checklists to perform routine audits and regular maintenance \\
- Assure workers know about required procedures and obtain feedback \\
- Offer training and coaching \\
- Encourage workers to speak up about how procedures can be done better to reward them for their contribution \\
Plan for auditing and using safety checklists
\end{tabular}




\section{Conclusion}

In the current study, the application of grounded theory has led to the development of practical actions (Table 8) to outperform the $5 \mathrm{~S}$ system performance in the electrical construction work zones. It should be noted that these quick guides can easily be applied as a checklist that covers fundamental tips in the $5 \mathrm{~S}$ methodology. Based on the interview analysis, the following conclusions, which are based on the expert's experience in real projects using the $5 \mathrm{~S}$ method, can be drawn:

- The results confirm that removing unwanted equipment in the sort step can diminish workers' exposure to disorganized material. This leads to a safety enhancement due to hazard and risk control strategy. Furthermore, Just-in-Time delivery could also support the sort step by preventing the items from piling up at the job site

- The research findings also revealed that setting materials and equipment in order actively minimize human errors for item selection and diminish the searching time. This means saving time and money. Indeed, safety will be improved accordingly

- Considering the interviews, Sweep step benefits are: A cleaner environment, improved quality and equipment lifespan, all of which support improved safety and lead to fewer accidents

- Applying grounded theory provided evidence that adopting a standard simplifies job duties and remove possible hazards. Conspicuously, visualization can play an essential role in this matter

- The interviewees' narrative analysis results showed that executing the Sustain step leads to better teamwork, a safe environment and the provision of safety managers with the data for safety augmentation purposes

In conclusion, the results of this study will provide practical guidelines and ideas to support employees at the performing level and project managers at the management levels in order to create a safer work environment. It is expected that these practical activities outperform the outcome of existing $5 \mathrm{~S}$ users or maximize their impact for the first-time users.

\section{Limitations and Future Research}

The results of this qualitative study should not be generalized to the whole construction industry due to the following limitations. Firstly, only 18 experts in the construction companies were interviewed that which may limit the validity of the study. Second, we visited just three job sites implementing $5 \mathrm{~S}$ for safety. There is a chance that the $5 \mathrm{~S}$ safety mechanism could be suitable just for a specific type of project and/or product. Third, even validity and credibility approaches were employed, coding of the interviewees in the grounded theory method could be affected by the bias of the researchers. However, it was crucial to let the classifications emerge from the data in the absence of standardized classifications. By doing so, researchers' bias is likely and the interpretation of the words of the interviewees might be influenced by the researchers (Mac Donald et al., 2020). Despite these limitations, the study still provides a significant contribution to the practices of safety by helping workers and managers adopt reliable safety methods and integrate them into $5 \mathrm{~S}$ steps. Ultimately, future research can test the proposed checklist through a mixed-methods analysis to explore the strength/weaknesses of it in electrical construction work environments.

\section{Funding Information}

Funding and support for this project have been provided by the State of Washington, Department of Labor and Industries, Safety and Health Investment Projects (Project \# 2017ZH00349) in the USA. Any opinions, conclusions and recommendations expressed in this study are those of the authors and do not necessarily reflect the views of the State, the Department, or the study participants.

\section{Author's Contributions}

Mohammad Sadra Fardhosseini: Writing part of introduction, collecting data, writing part of discussion and the results.

Mostafa Soltaninejad: Writing the title, the abstract and the introduction, methodology and Appendix. Discussing the results.

Ali Karji: Helping with introduction, data collection, results, discussion and conclusion.

Zahra Ghorbani: Helping with data collection and conclusion.

Omidreza Ghanadiof: Proofread the paper and leading and advising the study direction on data collection, methodology, discussion and conclusion.

\section{Ethics}

This article is original and contains unpublished material. It is confirmed that all of the authors have read and approved the manuscript and there are no ethical issues involved. 


\section{References}

Ab Rahman, M. N., Khamis, N. K., Zain, R. M., Deros, B. M., \& Mahmood, W. H. W. (2010). Implementation of $5 \mathrm{~S}$ practices in the manufacturing companies: A case study. American Journal of Applied Sciences, 7(8), 1182-1189. doi.org/10.3844/ajassp.2010.1182.1189

Al Heet, M. R. A. H., Alves, T. C. L., \& Lakrori, N. (2020). Investigation of the use of Lean Construction Practices in Transportation Construction Projects. Proceedings of $28^{\text {th }}$ Annual Conference of the International Group for Lean Construction (IGLC28), Berkeley, California, USA. doi.org/10.24928/2020/0121

Al-Aomar, R. A. (2011). Applying 5S LEAN Technology: An infrastructure for continuous process improvement. World Academy of Science, Engineering and Technology, 59(2011), 2014-2019.

Albrechtsen, E., Solberg, I., \& Svensli, E. (2019). The application and benefits of job safety analysis. Safety Science, 113, 425-437. doi.org/10.1016/j.ssci.2018.12.007

Aslam, M., Gao, Z., \& Smith, G. (2020a). Framework for selection of lean construction tools based on lean objectives and functionalities. International Journal of Construction Management, 1-12. doi.org/10.1080/15623599.2020.1729933

Aslam, M., Gao, Z., \& Smith, G. (2020b). Development of Innovative Integrated Last Planner System (ILPS). International Journal of Civil Engineering, 1-15.

Berroir, F., Harbouche, L., \& Boton, C. (2015, July). Top down vs. Bottom-up approaches regarding the implementation of lean construction through a French case study. In $23^{\text {rd }}$ Annual Conference of the International Group for Lean Construction (pp. 73-82).

Brown, G. D., \& O'rourke, D. (2007). Lean manufacturing comes to China: A case study of its impact on workplace health and safety. International Journal of Occupational and Environmental Health, 13(3), 249-257. doi.org/10.1179/oeh.2007.13.3.249

Bulawa, P. (2014). Adapting grounded theory in qualitative research: Reflections from personal experience. International Research in Education, 2, 79-114. doi.org/10.5296/ire.v2i1.4921

BLS. (2018). Injuries, illnesses and fatalities.

Creswell, J. W., \& Báez, J. C. (2020). 30 essential skills for the qualitative researcher. Sage Publications.

Denzin, N. K., \& Lincoln, Y. S. (Eds.). (2011). The Sage handbook of qualitative research. sage.

Diekmann, J. E., Krewedl, M., Balonick, J., Stewart, T., \& Won, S. (2004). Application of lean manufacturing principles to construction. Boulder, CO, Construction Industry Institute, 191.
Dudek-Burlikowska, M. (2006). Quality research methods as a factor of improvement of preproduction sphere. Journal of Achievements in Materials and Manufacturing Engineering, 18(1-2), 435-438.

Enshassi, A., \& Abu Zaiter, M. (2014, June). Implementation of lean tools on safety in construction projects in Palestine. In $22^{\text {nd }}$ annual conference Proceedings IGLC, Oslo, Norway (pp. 1205-1218).

Filip, F. C., \& Marascu-Klein, V. (2015, October). The $5 \mathrm{~S}$ lean method as a tool of industrial management performances. In IOP conference series: Materials science and engineering (Vol. 95, No. 1, p. 012127). IOP Publishing. doi.org/10.1088/1757-899X/95/1/012127

Gambatese, J. A., Pestana, C., \& Lee, H. W. (2017). Alignment between lean principles and practices and worker safety behavior. Journal of Construction Engineering and Management, 143(1), 04016083. doi.org/10.1061/(ASCE)CO.1943-7862.0001209

Gapp, R., Fisher, R., \& Kobayashi, K. (2008). Implementing $5 \mathrm{~S}$ within a Japanese context: An integrated management system. Management Decision.

Ghanadiof, O. (2017). Customer Loyalty and Powerful Brand in Heavy Machinery Industry: A Case Study at Technocat". Businesses Management Administration-Marketing: Thesis, Dissertations and Student Research.

Gupta, S., \& Jain, S. K. (2015). An application of 5S concept to organize the workplace at a scientific instruments manufacturing company. International Journal of Lean Six Sigma. doi.org/10.1108/IJLSS08-2013-0047

Harrington, H. J. (1991). P. American Society for Quality Control Quality, Business process improvement: The breakthrough strategy for total quality, productivity and competitiveness.

Innella, F., Arashpour, M., \& Bai, Y. (2019). Lean methodologies and techniques for modular construction: Chronological and critical review. Journal of Construction Engineering and Management, 145(12), 04019076. doi.org/10.1061/(ASCE)CO.1943-7862.0001712

Jaca, C., Viles, E., Paipa-Galeano, L., Santos, J., \& Mateo, R. (2014). Learning 5S principles from Japanese best practitioners: Case studies of five manufacturing companies. International Journal of Production Research, 52(15), 4574-4586. doi.org/10.1080/00207543.2013.878481

Jiménez, M., Romero, L., Domínguez, M., \& del Mar Espinosa, M. (2015). 5S methodology implementation in the laboratories of an industrial engineering university school. Safety Science, 78, 163-172. 
Jones, E. G., Soltaninejad, M., \& Ponce de Leon, C. (2019). Work in Progress: Moving from Outside to Inside-Traffic Engineering Field Exercises through Virtual Reality. Proceedings of the American Society for Engineering Education, Tampa, FL, USA, 15-19.

Lancucki, J. (2001). Basis of total quality management. AE, Poznan.

Lee, H. W., Gambatese, J. A., Kim, Y. W, Fardhosseini, M. S, Stuart, J., \& Reigelsperger, C. (2019). Lean and Safety Manual for Electrical Construction. https://www.researchgate.net/publication/33375917 5_Lean_and_Safety_Manual_for_Electrical_Constr uction

Leino, A., Heinonen, R., \& Kiurula, M. (2014). Improving safety performance through $5 \mathrm{~s}$ program. In Proc $22^{\text {nd }}$ Ann Conf of the Int'l Group for Lean Construction.

Low, S. P., \& Ang, G. K. (2003). Integrating JIT and 5-S concepts for construction site management: A case study. International Journal of Construction Management, 3(1), 31-47. doi.org/10.1080/15623599.2003.10773034

Mac Donald, K., Rezania, D., \& Baker, R. (2020). A grounded theory examination of project managers' accountability. International Journal of Project Management, 38(1), 27-35.

doi.org/10.1016/j.ijproman.2019.09.008

Meiling, J., Backlund, F., \& Johnsson, H. (2012). Managing for continuous improvement in off-site construction. Engineering, Construction and Architectural Management. doi.org/10.1108/09699981211206089

Michalska, J., \& Szewieczek, D. (2007). The 5S methodology as a tool for improving the organization. Journal of achievements in materials and manufacturing engineering, 24(2), 211-214.

Nelson, L. K. (2020). Computational grounded theory: A methodological framework. Sociological Methods \& Research, 49(1), 3-42. doi.org/10.1177/0049124117729703

Ng, K., Laurlund, A., Howell, G., \& Lancos, G. (2010). An experiment with leading indicators for safety. In Proceedings of the $18^{\text {th }}$ Annual Conference of IGLC (pp. 253-262). Haifa, Israel: IGLC.

OSHA. (2016). Business Case for Safety and Health. Occupational Safety and Health Administration. https://www.osha.gov/businesscase

Patton, M. Q. (1999). Enhancing the quality and credibility of qualitative analysis. Health services Research, 34(5 Pt 2), 1189.
Ruiz, C., Castillo, T., \& Paredes, M. (2020). Effects of implementation of $5 \mathrm{~s}$ in heavy equipment maintenance workshops. doi.org/10.24928/2020/0010

Salem, O., Pirzadeh, S., Ghorai, S., \& Abdel-Rahim, A. (2014, January). Reducing environmental, economic and social impacts of work-zones by implementing Lean Construction techniques. In Annual Conference of the International Group for Lean Construction (Vol. 22, pp. 145-155).

Salem, O., Solomon, J., Genaidy, A., \& Luegring, M. (2005). Site implementation and assessment of lean construction techniques. Lean Construction Journal, 2(2), 1-21. doi.org/10.1080/17457300.2020.1835991

Sheykhfard, A., Haghighi, F., Nordfjærn, T., \& Soltaninejad, M. (2020). Structural equation modelling of potential risk factors for pedestrian accidents in rural and urban roads. International Journal of Injury Control and Safety Promotion, 1-12.

Sorooshian, S., Salimi, M., Bavani, S., \& Aminattaheri, H. (2012). Case report: Experience of $5 \mathrm{~S}$ implementation. Journal of Applied Sciences Research, 8(7), 3855-3859.

Srinivasan, S., Ikuma, L. H., Shakouri, M., Nahmens, I., \& Harvey, C. (2016). 5S impact on safety climate of manufacturing workers. Journal of Manufacturing Technology Management. doi.org/10.1108/JMTM07-2015-0053

Strauss, A., \& Corbin, J. (1990). Basics of qualitative research. Sage publications.

Park, S. C., Lee, S. C., Suárez-Barraza, M. F., \& Ramis-Pujol, J. (2012). An exploratory study of 5S: A multiple case study of multinational organizations in Mexico. Asian Journal on Quality. 13(1),77-99. doi.org/10.1108/15982681211237842

Tezel, A., Aziz, Z., Koskela, L., \& Tzortzopoulos, P. (2016). Benefits of visual management in the transportation sector.

Titu, M. A., Oprean, C., \& Grecu, D. (2010, March). Applying the Kaizen method and the $5 \mathrm{~S}$ technique in the activity of post-sale services in the knowledge-based organization. In Proceedings of the International Multi Conference of Engineers and Computer Scientists (Vol. 3, pp. 17-19).

Varonen, U., \& Mattila, M. (2000). The safety climate and its relationship to safety practices, safety of the work environment and occupational accidents in eight wood-processing companies. Accident Analysis \& Prevention, 32(6), 761-769. doi.org/10.1016/S0001-4575(99)00129-3

Veres, C., Marian, L., Moica, S., \& Al-Akel, K. (2018). Case study concerning $5 \mathrm{~S}$ method impact in an automotive company. Procedia Manufacturing, 22, 900-905. doi.org/10.1016/j.promfg.2018.03.127 
Appendix A: Summary of 5S case studies based on objectives, methodologies and results (2003-2020)

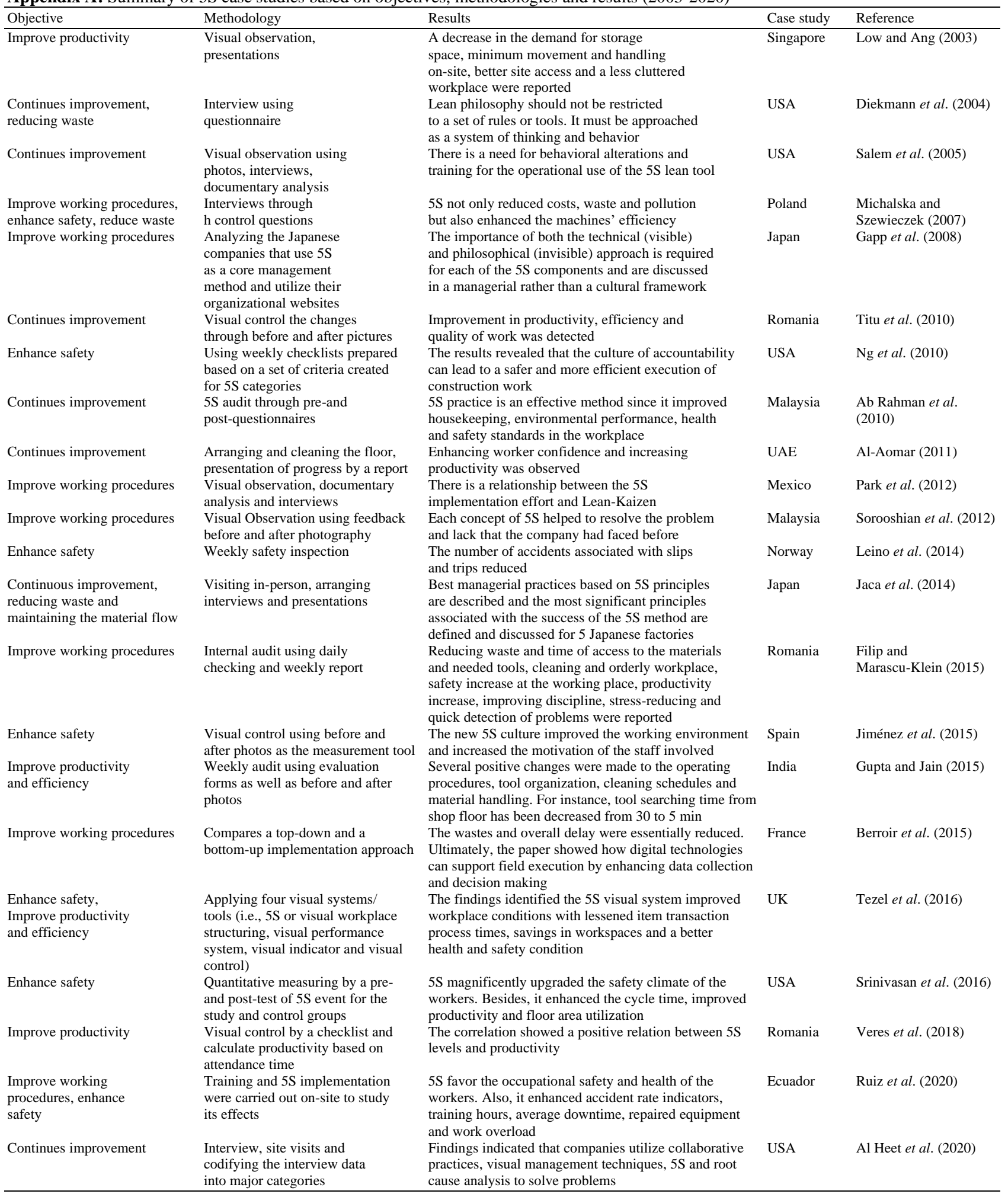

